\title{
Online Dead Time Effect Compensation Algorithm of PWM Inverter for Motor Drive Using PR Controller
}

\author{
Chang-Seok Park* and Tae-Uk Jung ${ }^{\dagger}$
}

\begin{abstract}
This paper proposes the dead time effect compensation algorithm using proportional resonant controller in pulse width modulation inverter of motor drive. To avoid a short circuit in the dc link, the dead time of the switch device is surely required. However, the dead time effect causes the phase current distortions, torque pulsations, and degradations of control performance. To solve these problems, the output current including ripple components on the synchronous reference frame and stationary reference frame are analyzed in detail. As a results, the distorted synchronous d-and q-axis currents contain the 6th, 12th, and the higher harmonic components due to the influence of dead time effect. In this paper, a new dead time effect compensation algorithm using proportional resonant controller is also proposed to reduce the output current harmonics due to the dead time and nonlinear characteristics of the switching devices. The proposed compensation algorithm does not require any additional hardware and the offline experimental measurements. The experimental results are presented to demonstrate the effectiveness of the proposed dead time effect compensation algorithm.
\end{abstract}

Key words: Dead time, Compensator, PWM inverter, PMSM drive

\section{Introduction}

Voltage Source Inverter(VSI) vector controlled motor drives have been widely developed. There are several causes to distort output voltage. Some is caused by the dead time that is to avoid shoot-through in the dc link. Others originate from the nonlinear characteristics of the switching devices such as turn-on/off time and voltages drop of switches and diodes. The distortion of the output voltage results in phase current distortions, torque pulsations, and degradations of control performance [1-5]. Since these undesirable ripples bring about bad influences to motor driving system, a compensation algorithm must be needed in the control algorithm of the motor drive. To solve the nonlinear characteristics of the VSI, various solutions have already been suggested [1-13]. The lost voltage average value calculation $[2,3]$, the pulse width modulation(PWM) pulse based technique [6]. voltage feed forward method [7-12], and the support vector regression(SVR) method [13] are the main categories of the conventional dead time compensation methods.

In PWM pulse based technique, the compensation is realized for each PWM pulse. In [8, 9], the methods are dependent on the phase current polarity. In the voltage feed forward method, the methods are based on a feedforward method, where the compensated voltages are fed to the reference voltages in order to generate a modified voltage.

$\dagger$ Corresponding Author: Dept. of Electrical Engineering, Kyungnam University, Korea. (tujung@kyungnam.ac.kr)

* Dept. of Electrical Engineering, Kyungnam University, Korea. (chang8793@naver.com)

Received: October 18, 2016; Accepted: January 28, 2017
The compensation voltages are calculated by using the dead time, switching period, current command, and dc-link voltage. This approach can compensate the fundamental and harmonic components of the voltage error in the dand q-axis frame. In the calculation of the compensating signals, nonlinear characteristics of the switching devices such as finite switching times and voltage drops are also considered. However, these methods can be implemented only by offline methods because the switching times and voltage drops of switching devices and diodes are varied with operating conditions such as dc-link voltage, phase currents, and motor speed. Thus, it is difficult to accurately compensate for the dead time effects by offline methods [12]. In [13], this method is based on an emerging learning technique SVR. The SVR technique is difficult to implement because SVR model method is required some parameters, online computation, and extra memory to construct the regression function.

In this paper, the output current including ripple components on the synchronous reference frame and stationary reference frame are analyzed in detail. Moreover, a new dead time effect compensation algorithm using proportional resonant(PR) controller is also proposed to reduce the output current harmonics due to the dead time and nonlinear characteristics of the switching devices The proposed compensation algorithm does not require any additional hardware and the off-line experimental to detect the dead time effect contrast with the existing method. Also, it is a very simple controller by adding feed-forward compensation. The simulation and the experimental results are presented to verify the usefulness of the proposed algorithm. 


\section{System Modeling}

\subsection{Dead time effects analysis $[4,15]$}

The switching device has a finite switching time, a blank-time or normally called dead-time must be inserted into the PWM gating signals in order to avoid the conduction overlap of two switching devices in the same leg. This dead-time causes the phase error, output voltage distortions and fundamental voltage drop, which degrade the control performance.

The commonly used three-phase PWM VSI whit a permanent magnet synchronous motor(PMSM) load is shown in Fig. 1.

Fig. 2(a) shows the a-phase current $i_{a s}$ flow in positive direction and Fig. 2(b) displayed the a-phase current $i_{a s}$ flow in negative direction in a-phase leg of the PWM VSI. In Fig. 2(a), the a-phase current $i_{a s}$ flows through switching device $S 1$ during the on-time of $S 1$. Conversely, the a-phase current $i_{a s}$ flows through diode of $S 2$ during both the off-time of $S 1$ and dead time $T_{\text {dead }}$. In Fig. 2(b), the a-phase current $i_{a s}$ flows through switching device $S 2$ during the on-time of $S 2$. Conversely, the a-phase current $i_{\text {as }}$ flows through diode of $S 1$ during both the off-

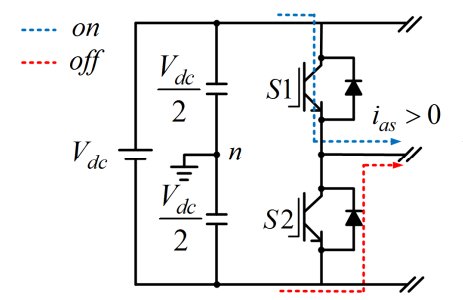

(a)

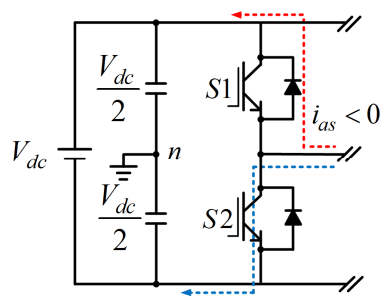

(b)
Fig. 2. Three-phase PWM VSI with PMSM load

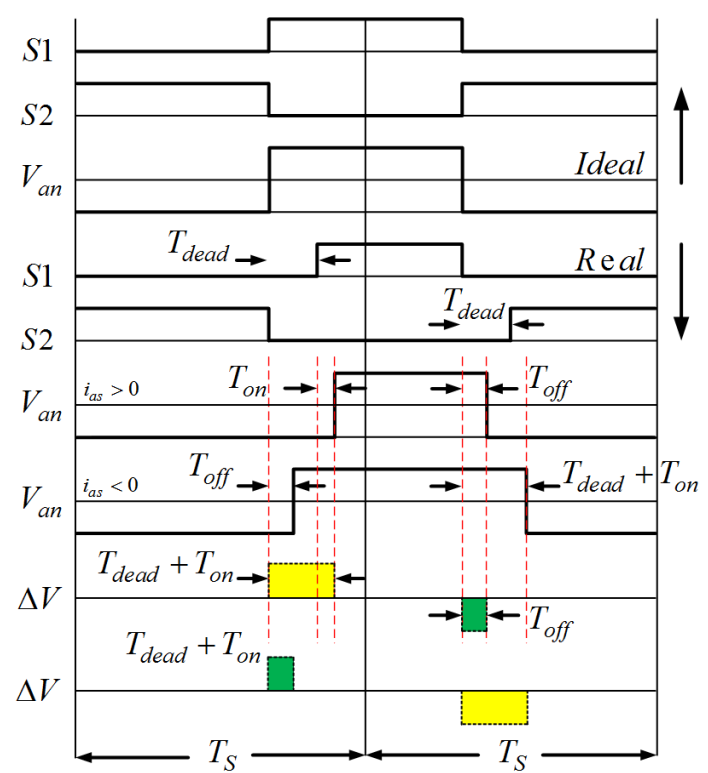

Fig. 3. Output voltage according to switching patterns time of $S 2$ and dead time $T_{\text {dead }}$. It means that the PWM VSI output voltage $V_{a n}$ has same characteristics during on, off-time of switching devices and during dead time $T_{\text {dead }}$. Hence, the PWM VSI output voltage $V_{a n}$ depends on the direction of the a-phase current $i_{a s}$.

The relationship between ideal and real PWM VSI output voltage in case of positive and negative current direction is shown in Fig. 3. Where $S 1$ and $S 2$ are PWM gate signal, $V_{a n}$ is output voltage of the PWM VSI, $\Delta V$ is the distorted voltage respectively. As shown in Fig. 3, the real output voltage $V_{a n}$ of PWM VSI is directly influenced by the dead time and turn-on/turn-off delay time of switching device.

From Fig. 3, the average distorted voltage $\Delta V$ according to the direction of the a-phase current $i_{a s}$ can be represented as $[14,15]$.

$$
\begin{gathered}
\Delta V=\frac{-T_{\text {dead }}-t_{o n}+t_{o f f}}{2 T_{S}} V_{d c} \quad\left(i_{a s}>0\right) \\
\Delta V=\frac{T_{\text {dead }}+t_{o n}-t_{o f f}}{2 T_{S}} V_{d c} \quad\left(i_{a s}<0\right)
\end{gathered}
$$

where $T_{S}$ is the sampling period of the current regulator, $t_{\text {on }}$ is the turn-on delay time of switching device, $t_{\text {off }}$ is the turn-on delay time of switching device, respectively.

The absence of a neutral connection in the motor forces the constraint that [7]:

$$
i_{a s}+i_{b s}+i_{c s}=0
$$

For any balanced load, the line to neutral voltages are constrained such that :

$$
V_{a s}+V_{b s}+V_{c s}=0
$$

Therefore, the distorted voltage of three-phases are calculated by (5).

$$
\begin{aligned}
& \Delta v_{a s}=\Delta V \frac{1}{3}\left\{2 \operatorname{sign}\left(i_{a s}\right)-\operatorname{sign}\left(i_{b s}\right)-\operatorname{sign}\left(i_{c s}\right)\right\} \\
& \Delta v_{b s}=\Delta V \frac{1}{3}\left\{2 \operatorname{sign}\left(i_{b s}\right)-\operatorname{sign}\left(i_{c s}\right)-\operatorname{sign}\left(i_{a s}\right)\right\} \\
& \Delta v_{c s}=\Delta V \frac{1}{3}\left\{2 \operatorname{sign}\left(i_{c s}\right)-\operatorname{sign}\left(i_{a s}\right)-\operatorname{sign}\left(i_{b s}\right)\right\}
\end{aligned}
$$

If the phase current flow in positive direction, $\operatorname{sign}\left(i_{a s, b s, c s}\right)$ is +1 . Conversely, if the phase current flow in negative direction, $\operatorname{sign}\left(i_{a s, b s, c s}\right)$ is -1 .

By (5), the distorted phase voltage $\Delta v_{s}$ and three-phase current $i_{s}$ can be drawn as Fig. 4. Also, Fig. 5. is shown the distorted voltage and the $d q$-axis currents of the stationary reference frame.

In order to analysis the harmonic component by dead time effect, Fourier series is applied. In case of square- 

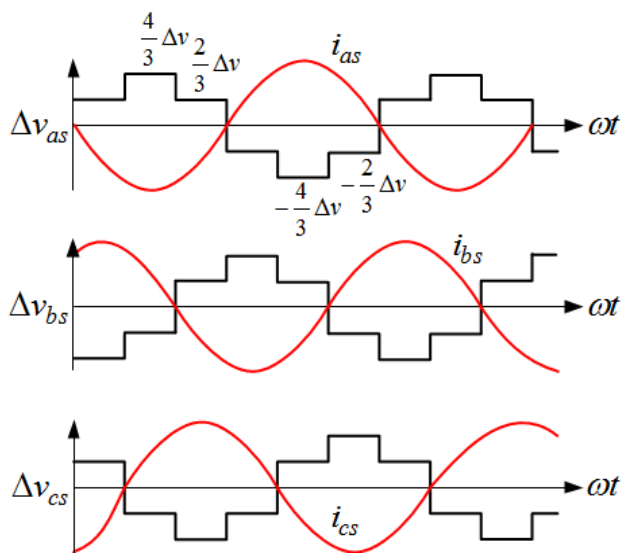

Fig. 4. Distorted phase voltage and phase current in PWM VSI
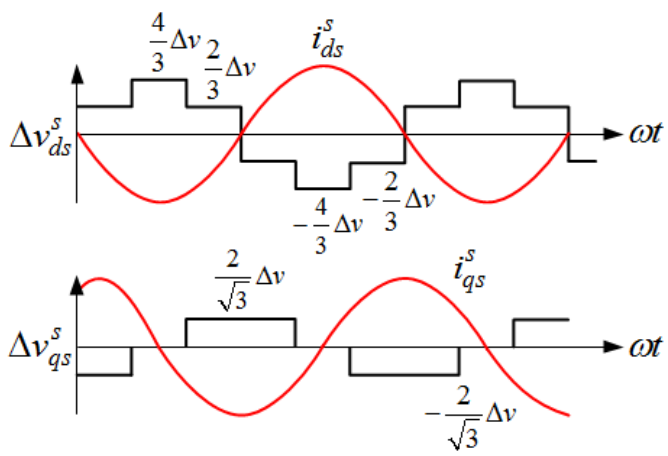

Fig. 5. Distorted voltage and the $d q$-axis currents of the stationary reference frame

wave voltage, the harmonic component of voltage is calculated as follows:

$$
v_{h}=\frac{4 V_{d c}}{\pi} \sum_{h=1,3,5,7 \ldots}^{\infty} \frac{1}{h} \sin \left(h \omega_{0} t\right)
$$

where $v_{h}$ is the harmonic component of voltage, $V_{d c}$ is the square-wave voltage, $h$ is harmonic order and $\omega_{0}$ is the motor synchronous frequency ( $\mathrm{rad} / \mathrm{s})$.

Therefore, the distorted voltage $\Delta v_{d s}^{s}$ and $\Delta v_{q s}^{s}$ can be obtained by (7), (8).

$$
\begin{aligned}
\Delta v_{d s}^{s}=\frac{4 \Delta V}{\pi} & \left\{\sin \omega_{0} t+\frac{1}{5} \sin 5 \omega_{0} t+\frac{1}{7} \sin 7 \omega_{0} t\right. \\
& \left.+\frac{1}{11} \sin 11 \omega_{0} t+\frac{1}{13} \sin 13 \omega_{0} t+\ldots\right\} \\
\Delta v_{q s}^{s}=\frac{4 \Delta V}{\pi}\{ & -\cos \omega_{0} t+\frac{1}{5} \cos 5 \omega_{0} t-\frac{1}{7} \cos 7 \omega_{0} t \\
& \left.+\frac{1}{11} \cos 11 \omega_{0} t-\frac{1}{13} \cos 13 \omega_{0} t+\ldots\right\}
\end{aligned}
$$

Similarly, the distorted current $i_{h}$ which corresponds to the distorted voltage can be calculated by (9).

$$
i_{h}=\frac{4 \Delta v_{s}}{\pi} \sum_{h=1,3,5,7 \ldots}^{\infty} \frac{1}{h Z_{h}} \sin \left(h \omega_{0} t-\phi_{h}\right)
$$

where $Z_{h}$ is the load impedance, $\phi_{h}$ is the load impedance angle respectively.

From (9), the distorted $d p$-axis currents of the stationary reference frame can be expressed as (10), (11).

$$
\begin{aligned}
\Delta i_{d s}^{s}= & \frac{4 \Delta V}{\pi}\left\{\frac{\sin }{Z}\left(\omega_{0} t-\phi\right)+\frac{1}{5 Z_{5}} \sin \left(5 \omega_{0} t-\phi_{5}\right)\right. \\
& +\frac{1}{7 Z_{7}} \sin \left(7 \omega_{0} t-\phi_{7}\right)+\frac{1}{11 Z_{11}} \sin \left(11 \omega_{0} t-\phi_{11}\right) \\
& \left.+\frac{1}{13 Z_{13}} \sin \left(13 \omega_{0} t-\phi_{13}\right)+\ldots\right\} \\
\Delta i_{q s}^{s}= & \frac{4 \Delta V}{\pi}\left\{-\frac{\cos }{Z}\left(\omega_{0} t-\phi\right)+\frac{1}{5 Z_{5}} \cos \left(5 \omega_{0} t-\phi_{5}\right)\right. \\
& -\frac{1}{7 Z_{7}} \cos \left(7 \omega_{0} t-\phi_{7}\right)+\frac{1}{11 Z_{11}} \cos \left(11 \omega_{0} t-\phi_{11}\right) \\
& \left.-\frac{1}{13 Z_{13}} \cos \left(13 \omega_{0} t-\phi_{13}\right)+\ldots\right\}
\end{aligned}
$$

In order to simple analysis, the distorted voltages and the distorted currents of the synchronous reference frame can be rewritten by (12)-(15).

$$
\begin{aligned}
\Delta v_{d s}^{e}= & \frac{4 \Delta V}{\pi}\left\{\frac{12}{35} \sin 6 \omega_{0} t+\frac{24}{143} \sin 12 \omega_{0} t+\cdots\right\} \\
\Delta v_{q s}^{e}= & \frac{4 \Delta V}{\pi}\left\{-1+\frac{2}{35} \cos 6 \omega_{0} t+\frac{2}{143} \cos 12 \omega_{0} t+\cdots\right\} \\
\Delta i_{d s}^{e}= & \frac{4 \Delta V}{\pi}\left\{\frac{12}{35 Z_{6}} \sin \left(6 \omega_{0} t-\phi_{6}\right)\right. \\
& \left.\quad+\frac{24}{143 Z_{12}} \sin \left(12 \omega_{0} t-\phi_{12}\right)+\cdots\right\} \\
\Delta i_{q s}^{e}= & \frac{4 \Delta V}{\pi}\left\{-\frac{1}{Z}+\frac{2}{35 Z_{6}} \cos \left(6 \omega_{0} t-\phi_{6}\right)\right. \\
& \left.+\frac{2}{143 Z_{12}} \cos \left(12 \omega_{0} t-\phi_{12}\right)+\cdots\right\}
\end{aligned}
$$

As shown in (14) and (15), the distorted synchronous $\mathrm{d}$-and q-axis current contain the $6^{\text {th }}, 12^{\text {th }}$, and the higher harmonic components due to the influence of dead time effect. The $6^{\text {th }}$ harmonic component is dominated by (14) and (15). The dead time effect can be mitigated by the appropriately harmonic component mitigation, either in stationary or in synchronous reference frame.

\section{Proposed Dead Time Compensation Algorithm}

\subsection{Design of PR controller}

In general, PR controller is used to remove the certain 
order harmonics for the current regulator because the PR controller has zero steady-state error for sinusoidal waveforms having the same synchronous frequency as $\omega_{r}$ [16-19].

The ideal PR control, which is based on an internal modern theory, is expressed as (16).

$$
G_{S}=K_{P}+\frac{K_{i} s}{s^{2}+\omega_{r}^{2}}
$$

Where $\omega_{r}$ is the resonant frequency, $K_{P}$ and $K_{i}$ represent proportional and resonant gains respectively. For $K_{P}$, it is tuned in the same way as for a PI controller, and it basically determines the dynamics of the system in terms of bandwidth, phase and gain margin and $K_{i}$ could be tuned for shifting the magnitude response vertically but this does not give rise to a significant variation in bandwidth [20]. The Bode plots of ideal PR control method are shown in Fig. 6.

The ideal PR controller has an infinite gain at the resonant frequency and no phase shift and gain at other frequencies. However, the controller's infinite gain may cause stability problems and has the practical limitations of signal processing systems. Because of these problems, the non-ideal PR controller transfer function (17) is used instead of ideal PR controller (16).

$$
G_{S}=K_{P}+\frac{K_{i} \omega_{c} s}{s^{2}+2 \omega_{c} s+\omega_{r}^{2}}
$$

The Bode plots of non-ideal PR control method are shown in Fig. 7(a) and 7(b).

By applying the bilinear transformation $S_{Z}$ and substituting in to non-ideal trans function (17), the discrete trans function of the PR controller can be obtained by (18).

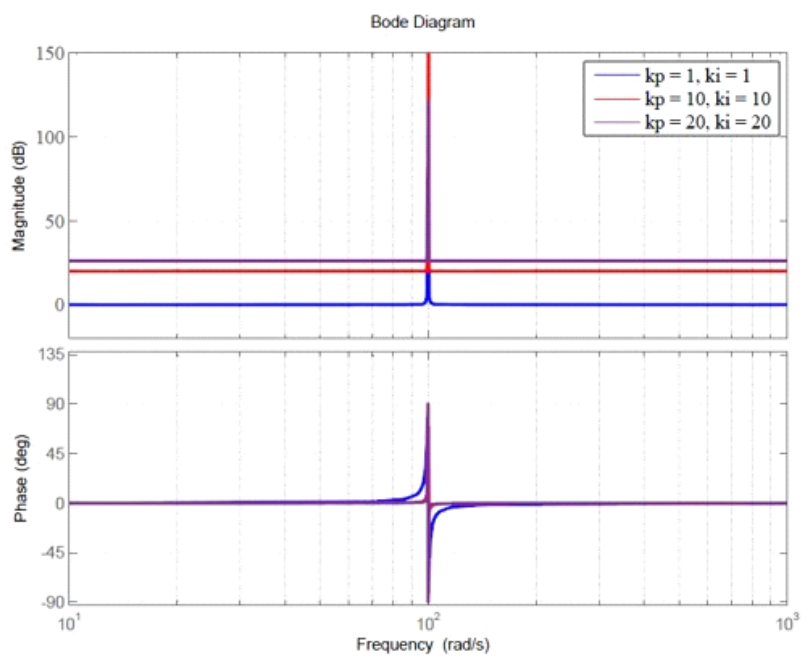

Fig. 6. Bode plots of ideal PR controller $\left(\omega_{0}=100[\mathrm{rad} / \mathrm{s}]\right)$

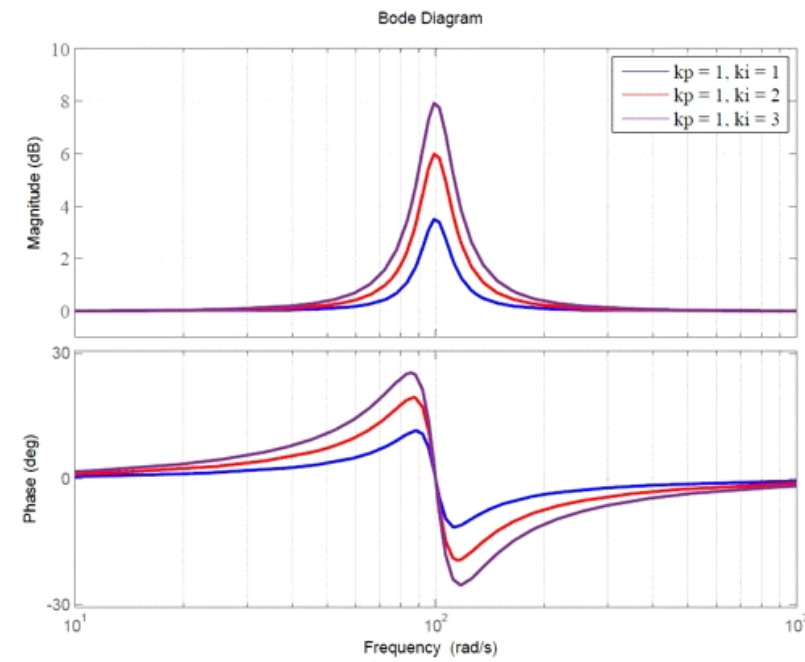

Fig. 7. Bode plots of non-ideal PR controller( $\omega_{c}: 10$ $\left.[\mathrm{rad} / \mathrm{s}], \quad \omega_{r}: 100[\mathrm{rad} / \mathrm{s}]\right)$

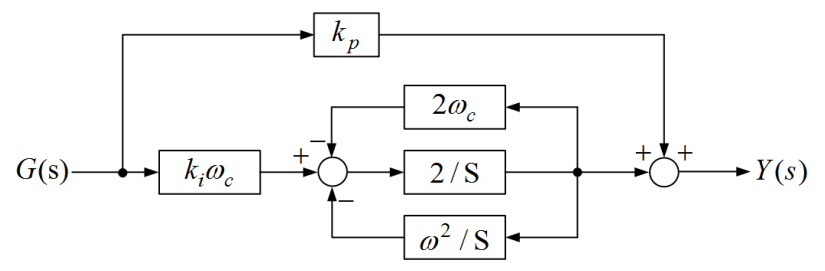

Fig. 8. Block diagram of non-ideal PR controller

$$
S_{Z}=\frac{2}{T_{S}} \frac{1-z^{-1}}{1+z^{-1}}, \quad G_{Z}=\frac{n_{0}+n_{1} z^{-1}+n_{2} z^{-2}}{1+d_{1} z^{-1}+d_{2} z^{-2}}
$$

where $T_{S}$ is the sampling time,

$$
\begin{aligned}
& n_{0}=\frac{\left(4+4 T_{S} \omega_{c}+\omega_{0}^{2} T_{S}^{2}\right) K_{p}+4 K_{i} T_{S} \omega_{c}}{4+4 T_{S} \omega_{c}+\omega_{0}^{2} T_{S}^{2}} ; \\
& n_{1}=\frac{\left(-8+2 \omega_{0}^{2} T_{S}^{2}\right) K_{p}}{4+4 T_{S} \omega_{c}+\omega_{0}^{2} T_{S}^{2}} ; \\
& n_{2}=\frac{\left(4-4 T_{S} \omega_{c}+\omega_{0}^{2} T_{S}^{2}\right) K_{p}-4 K_{i} T_{S} \omega_{c}}{4+4 T_{S} \omega_{c}+\omega_{0}^{2} T_{S}^{2}} ; \\
& d_{1}=\frac{-8+2 \omega_{0}^{2} T_{S}^{2}}{4+4 T_{S} \omega_{c}+\omega_{0}^{2} T_{S}^{2}} ; d_{2}=\frac{4-4 T_{S} \omega_{c}+\omega_{0}^{2} T_{S}^{2}}{4+4 T_{S} \omega_{c}+\omega_{0}^{2} T_{S}^{2}}
\end{aligned}
$$

Therefore, the digital equation of non-ideal PR controller can be given by (19).

$$
\begin{aligned}
y(k)= & n_{0} u(k)+n_{1} u(k-1)+n_{2} u(k-2) \\
& -d_{1} \mathrm{y}(k-1)-d_{2} \mathrm{y}(k-2)
\end{aligned}
$$

The block diagram of non-ideal PR controller is shown in Fig. 8. 


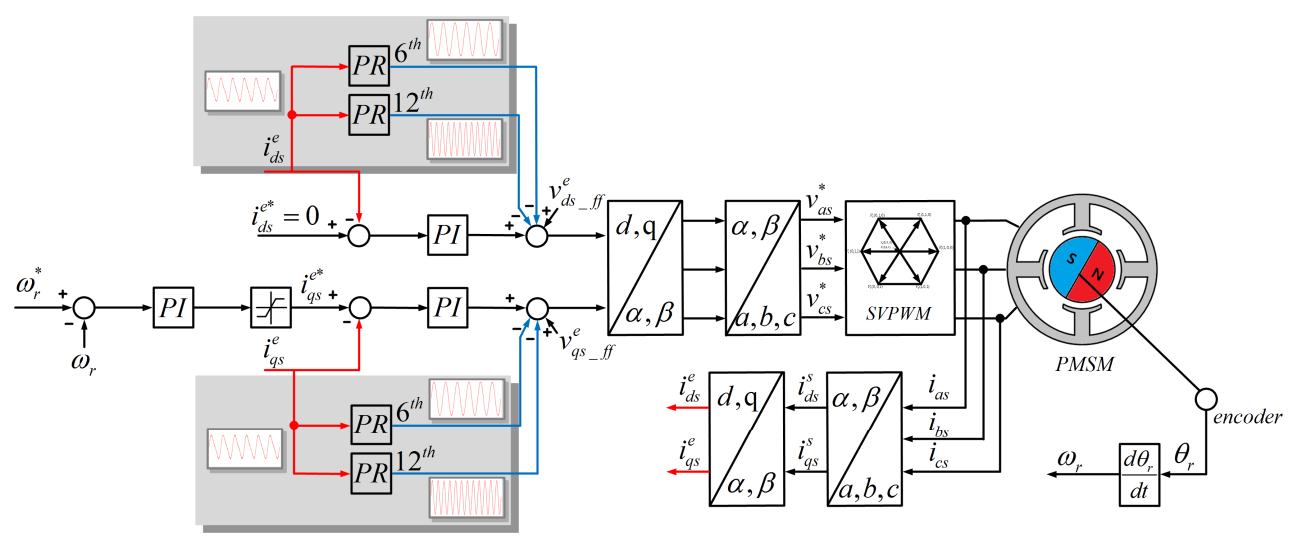

Fig. 9. Block diagram of the proposed dead time effect compensation algorithm

Table 1. The properties of a SPMSM drive parameter

\begin{tabular}{cc}
\hline Properties SPMSM & Details \\
\hline Rated voltage & $25[\mathrm{~V}]$ \\
Rated current & $2.8[\mathrm{~A}]$ \\
Rated speed & $3000[\mathrm{r} / \mathrm{min}]$ \\
Maximum speed & $3500[\mathrm{r} / \mathrm{min}]$ \\
Poles & 4 \\
Stator resistance & $0.75[\Omega]$ \\
Stator inductance & $0.85[\mathrm{mH}]$ \\
\hline Properties motor drive & Details \\
\hline Control processor & DSP TMS320F28335 \\
Switching frequency & $10[\mathrm{kHz}]$ \\
Current regulator period & $100[\mu s]$ \\
Speed regulator period & $1000[\mu s]$ \\
Dead time & $3[\mu s]$ \\
Turn on time of switch device & $0.1 \sim 0.4[\mu s]$ \\
Turn off time of switch device & $0.2 \sim 1.1[\mu s]$ \\
\hline &
\end{tabular}

\subsection{Proposed dead time compensation method}

The distorted synchronous d-and q-axis currents contain the $6^{\text {th }}, 12^{\text {th }}$, and the higher harmonic components due to the influence of dead time effect. Fig. 9. shows the block diagram of the proposed compensation algorithm.

Firstly, the synchronous d- and q-axis currents are passed through the PR controller to extract the $6^{\text {th }}, 12^{\text {th }}$ harmonics components in parallel with PI current regulator.

Secondly, the output of PR controller is used to feedforward compensation of PI current regulator output.

Hence, the harmonic components due to the dead time effect can be eliminated.

\section{Experimental Results}

The proposed dead time effect compensation algorithm was implemented with a SPMSM drive system. The parameters given in Table 1. The drive system for experimental is shown in Fig. 10.

Fig. 11(a), (b), and (c) show the experimental waveforms without the dead time compensation when the motor operates at $3000[\mathrm{r} / \mathrm{min}]$ at no-load. Fig. 11(a) displays

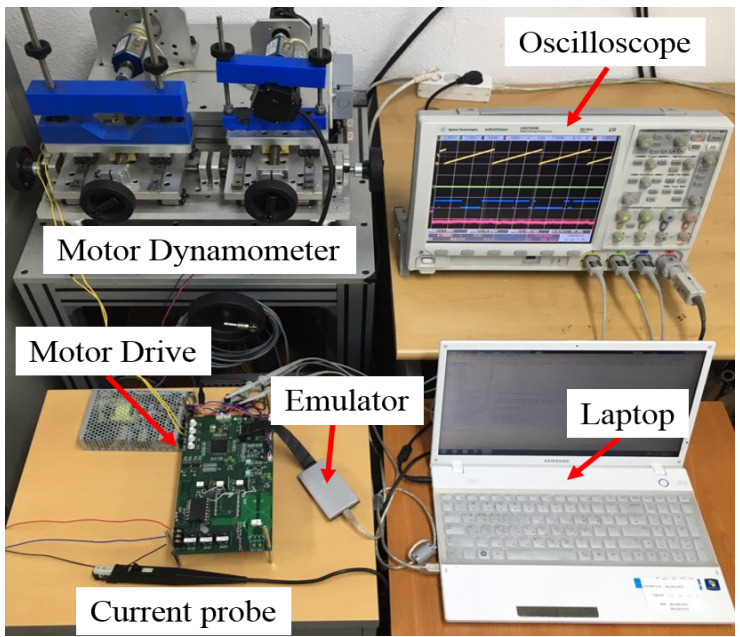

Fig. 10. Experimental system setup

the hexagonal $\mathrm{x}-\mathrm{y}$ plot. The phase current $i_{a s}$ with distorted waveform is shown in Fig. 11(b). As show in Fig. 11(b), the FFT result of the phase current $i_{a s}$ have the $5^{\text {th }}$ and $7^{\text {th }}$ harmonic components, and the higher harmonic components. However, the FFT result contains very small $11^{\text {th }}$ and $13^{\text {th }}$ harmonic components rather than $5^{\text {th }}$ and $7^{\text {th }}$ harmonic components by (10). It means that the distorted waveform is not significantly affected by the $11^{\text {th }}$ and $13^{\text {th }}$ harmonic components. The $\mathrm{d}$ - and q-axis currents of the synchronous reference frame have the $6^{\text {th }}$ harmonic component, as shown in Fig. 11(c).

Fig. 13 shows the experimental results waveforms of the proposed compensator. With the proposed method, the $x-y$ plot of the Fig. 12(a) displays circular waveforms rather than Fig. 11(a) and the phase current $i_{a s}$ has the nearly sinusoidal waveform as shown in Fig. 12(b). The harmonic components of the phase current $i_{a s}$ are considerably reduced by the proposed algorithm. Likewise, the dq-axes currents of the synchronous reference frame and the FFT results show the reduced harmonics, as shown in Fig. 12(c).

Fig. 13(a), (b), and (c) illustrate the experimental results without the dead time compensation when the motor operates at $3000[\mathrm{r} / \mathrm{min}]$ in the $30[\mathrm{~W}]$ output. Similar to the 


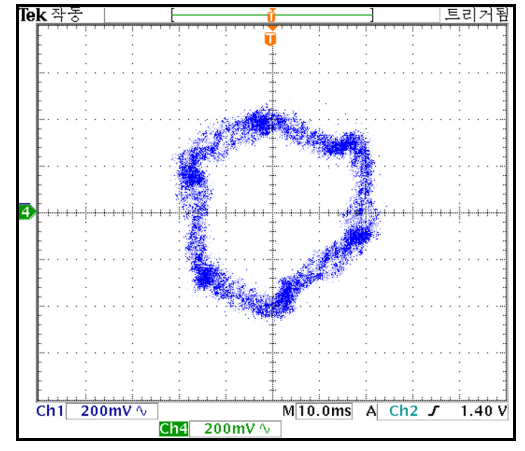

(a) $\mathrm{x}-\mathrm{y}$ plot

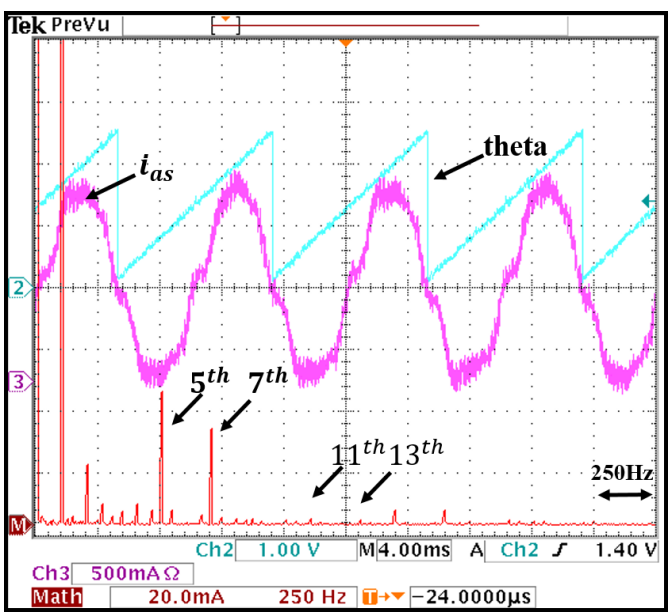

(b) harmonics of $i_{a s}\left(=i_{d s}^{s}\right)$ current

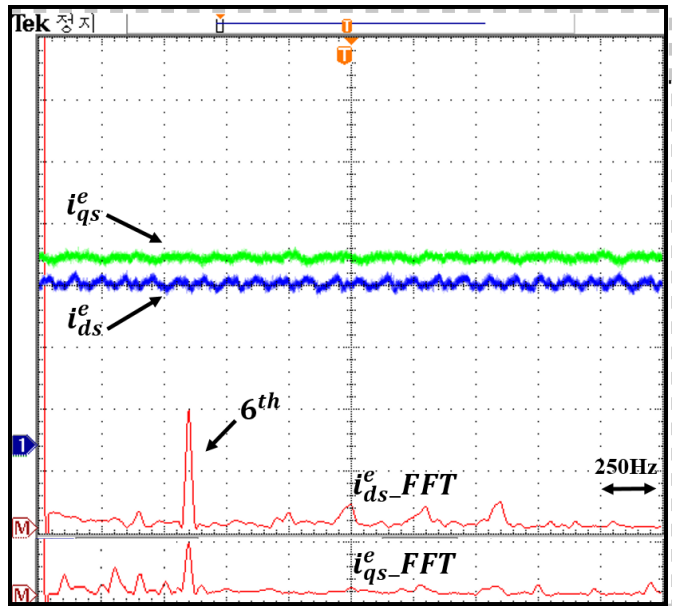

(c) harmonics of $d$ - and $q$-axis currents

Fig. 11. Current waveforms without dead time compensation under no-load

no-load condition, the $\mathrm{x}-\mathrm{y}$ plot of the stationary reference frame current $i_{d s}^{s}$ and $i_{q s}^{s}$ display the hexagonal wave form. The FFT result of the phase current $i_{a s}$ have the $5^{\text {th }}$ and $7^{\text {th }}$ harmonic components, and the higher harmonic components. Also, the FFT result contains small $11^{\text {th }}$ and $13^{\text {th }}$ harmonic components rather than $5^{\text {th }}$ and $7^{\text {th }}$ harmonics.

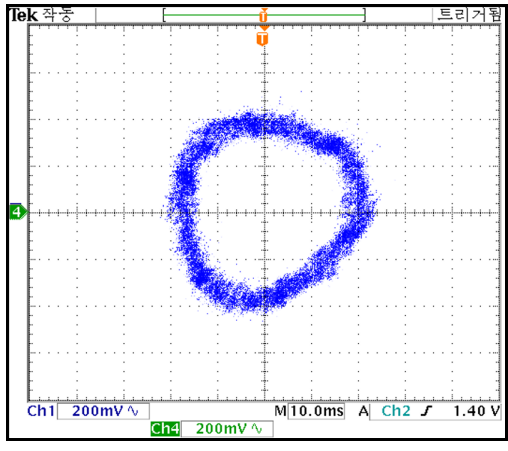

(a)x-y plot

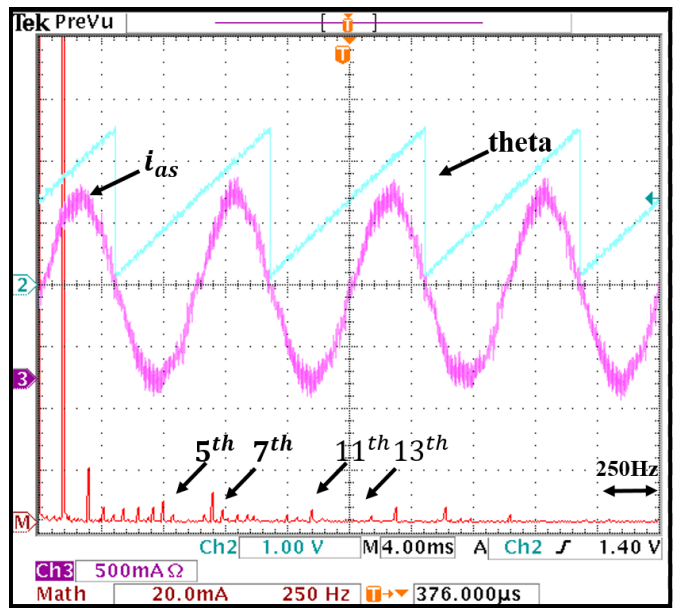

(b) harmonics of $i_{a s}\left(=i_{d s}^{s}\right)$ current

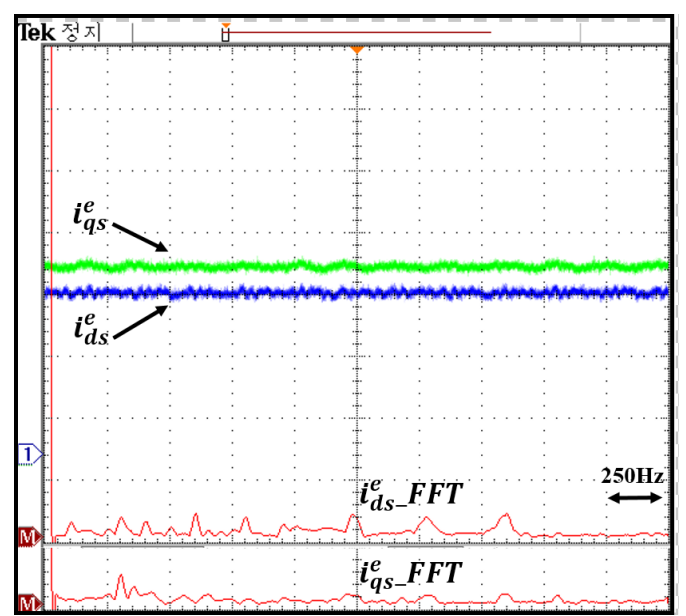

(c) harmonics of $d$ - and $q$-axis currents

Fig. 12. Current waveforms with dead time compensation under no-load

Considering the proposed dead time compensation algorithm, the x-y plot of the Fig. 14(a) shows circular waveforms rather than Fig. 13(a) and the phase current $i_{a s}$ has the pure sinusoidal waveform as shown in Fig. 14(b). The harmonics of the phase current $i_{a s}$ are considerably reduced by the dead time compensation. Likewise, the $d q$-axes currents of the synchronous 


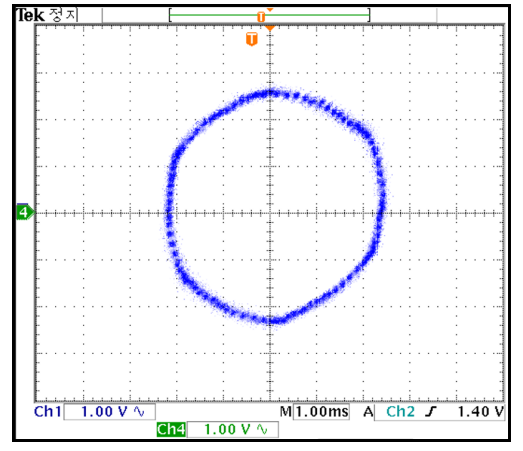

(a) $x-y$ plot

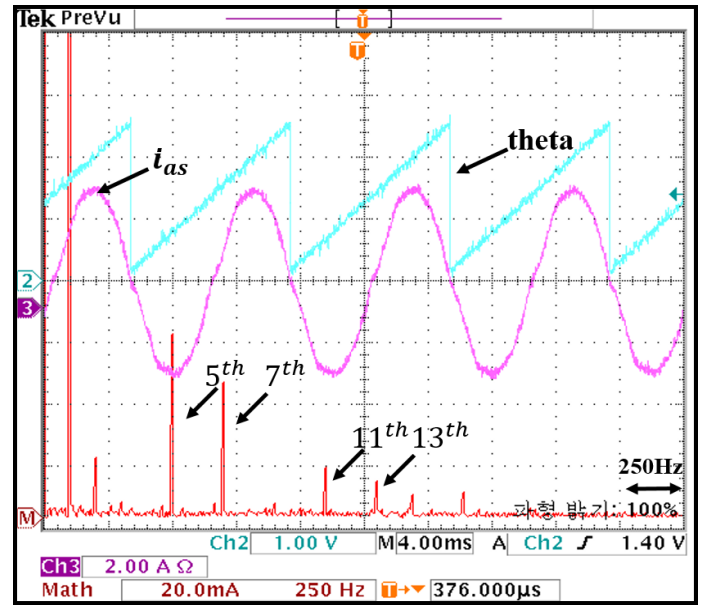

(b) harmonics of $i_{a s}\left(=i_{d s}^{s}\right)$ current

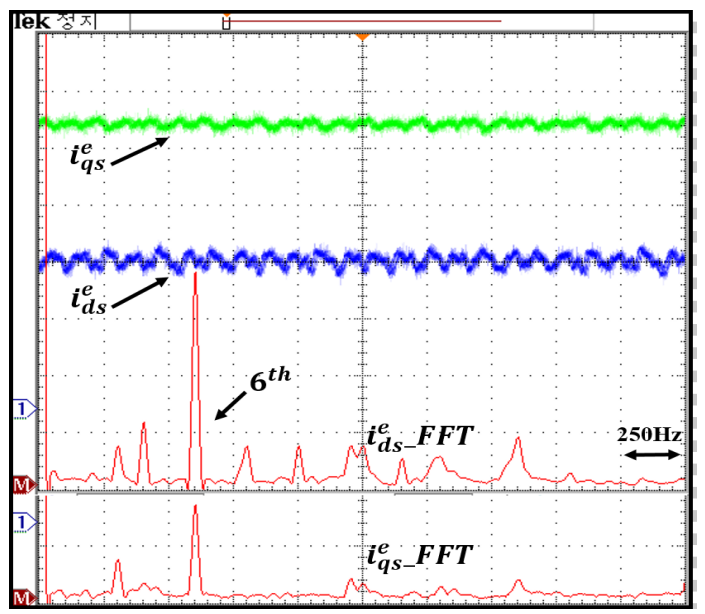

(c) harmonics of $d$ - and $q$-axis currents

Fig. 13. Current waveforms without dead time compensation under on-load

reference frame and the FFT results show the reduced harmonics, as shown in Fig. 14(c).

\section{Conclusions}

The dead time compensation algorithm for the motor

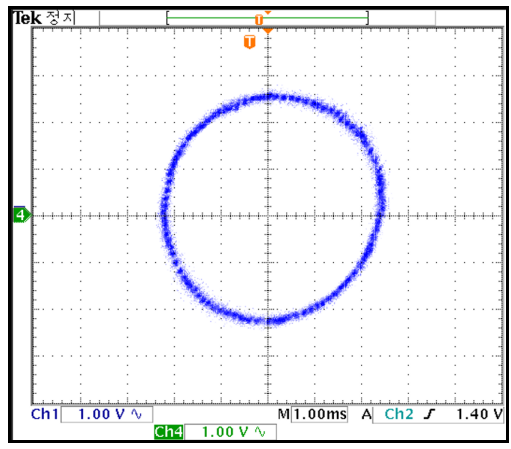

(a) $\mathrm{x}-\mathrm{y}$ plot

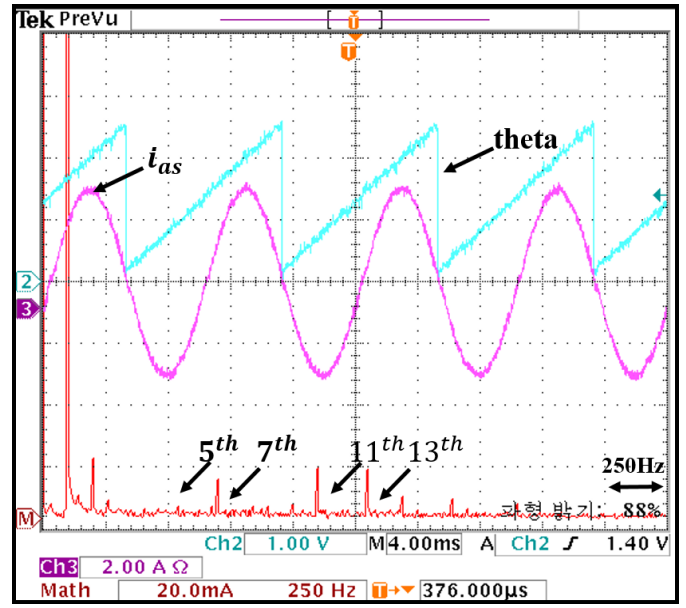

(b) harmonics of $i_{a s}\left(=i_{d s}^{s}\right)$ current

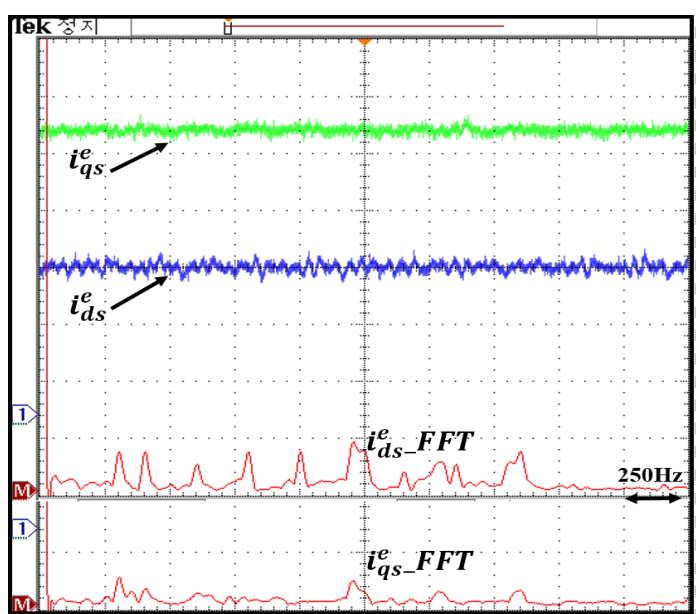

(c) harmonics of $d$ - and $q$-axis currents

Fig. 14. Current waveforms with dead time compensation under on-load

drive system is proposed. The proposed algorithm is comprised of the PR controller in parallel with the general PI current regulator. The output of PR controller is used to feed-forward compensation of PI current regulator output. Hence, the harmonic components due to the dead time effect can be eliminated.

This algorithm does not require any external hard ware, 
off-line experimental measurements. The proposed method can be easily implemented and applied in the system. The validity of the proposed algorithm is proved by the several experimental tests.

\section{Acknowledgements}

This work was supported by the Kyungnam University Foundation Grant, 2016.

\section{References}

[1] A. Aimad, K. Madjid, and S. Mekhilef, "Robust Sensorless Sliding Mode Flux Observer for DTCSVM-based Drive with Inverter Nonlinearity Compensation," Journal of Power Electronics, vol. 14, no. 1, pp. 125-134, 2014.

[2] K. Koga, R. Ueda, and T. Sonoda, "Stability Problem in Induction Motor Drive System," IEEE IAS Annua. Meeting, pp. 129-136, 1988.

[3] F. Blaabjerg and J. K. Pedersen, "Ideal PWM-VSI Inverter using Only One Current Sensor in the dcLink," IEEE 5th Power Electronics and VariableSpeed Drives Conference, pp. 458-464, October 1994.

[4] J. Shi, S. Li, "Analysis and Compensation Control of Dead-Time Effect on Space Vector PWM," Journal of Power Electronics, vol. 15, no. 2, pp. 431442, 2015.

[5] K. C. Kim “Analysis on Core Loss of Brushless DC Motor Considering Pulse Width Modulation of Inverter," Journal of Electrical Engineering \& Technology, vol. 9, no. 6, pp. 1914-1920, 2014.

[6] Seung-Gi Jeong and Min-Ho Park, "The Analysis and Compensation of Dead-time Effect in PWM Inverters," IEEE Transactions on Industrial Electronics, vol. 38, no. 2, pp. 108-114, April 1991.

[7] D. Leggate and R. Kerkman, "Pulse-based Dead-time Compensator for PWM Voltage Inverters," IEEE Trans. Ind. Electron., vol. 38, no. 2, pp. 191-197, Apr. 1997.

[8] J. W. Choi and S. K. Sul, "A New Compensation Strategy Reducing Voltage/Current Distortion in PWM VSI Systems Operating with Low Output Voltages," IEEE Transactions on Industry Application, vol. 31, no. 5, pp. 1001-1008, September./ October 1995.

[9] T. Sukegawa, K. Mizuno, T. Matsui, and T. Okuyama, "Fully Digital, Vector Controlled PWM VSI-fed ac Drives with an Inverter Dead-time Compensation Strategy," IEEE Trans. Ind. Appl., vol. 27, no. 3, pp. 552- 559, May/Jun. 1991.

[10] H. Zhao, Q. M. J. Wu, and A. Kawamura, “An
Accurate Approach of Nonlinearity Compensation for VSI Inverter Output Voltage," IEEE Trans. Power Electron., vol. 19, no. 14, pp. 1029-1035, Jul. 2004.

[11] A. Cichowski and J. Nieznanski, "Self-tuning Deadtime Compensation Method for Voltage-source Inverters," IEEE Power Electron. Lett., vol. 3, no. 2, pp. 72-75, Jun. 2005.

[12] S. Sayeef and M. F. Rahman, "Improved Flux and Torque Estimators of a Direct Torque Controlled Interior PM Machine with Compensations for Dead-time Effects and Forward Voltage Drops," IEEE Trans. Power Electron., vol. 9, no. 3, pp. 438446, May 2009.

[13] K. R. Cho and J. K. Seok, "Inverter Nonliearity Compensation in the Presence of Current Measurement Errors and Switching Device Parameter Uncertainties," IEEE Trans. Power Electron., vol. 22, no. 2, pp. 576-583, Mar. 2007.

[14] M. S. Manoharan, A. Ahmed and J. H. Park "PeakValley Current Mode Controlled H-Bridge Inverter with Digital Slope Compensation for Cycle-byCycle Current Regulation," Journal of Electrical Engineering \& Technology, vol. 10, no. 5, pp. 19892000, 2015.

[15] S. H. Hwang and J. M. Kim, "Dead Time Compensation Method for Voltage-fed Pwm Inverter," IEEE Trans. Energy Convers., vol. 25, no. 1, pp. 1-10, Mar. 2010.

[16] R. Teodorescu, M. Liserre, and P. Rodríguez, "Grid Converters for Photovoltaic and Wind Power Systems," John Wiley \& Sons, Ltd, 2011.

[17] M. Ebad and B. Song, "Improved Design and Control of Proportional Resonant Controller for Three-Phase Voltage Source Inverter," in IEEE Conference Publications, 2012.

[18] Rodriguez, P.; Luna, A.; Munoz-Aguilar, R.; Etxeberria-Otadui, I.; Teodorescu, R.; Blaabjerg, F. "A Stationary Reference Frame Grid Synchronization System for Three-phase Grid-connected Power Converters under Adverse Grid Conditions," IEEE Trans. Power Electron. 2011, 27, 99-112.

[19] Y. Lyu, H. Lin, "Simplified Controller Design Method for Digitally Controlled LCL-Type PWM Converter with Multi-resonant Quasi-PR Controller and Capacitor-Current-Feedback Active Damping," Journal of Power Electronics, vol. 14, no. 6, pp. 1322-1333, 2014.

[20] Ahmed, K. H., Massoud, A. M., Finney, S.J.; Williams, B.W. "A Modified Stationary Reference Frame Based Predictive Current Control with Zero Steady-state Error for LCL Coupled Inverter-based Distributed Generation Systems," IEEE Trans. Power Electron. 2011, 58, 1359-1370. 


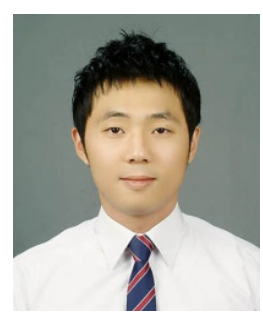

Chang-Seok Park was born in Changwon, Korea, in 1987. He received the B.S., M.S. degree in electrical engineering from Kyungnam University, Changwon, Korea, in 2012, 2014 respectively. He is currently a Ph.D. student at Kyungnam University. His main research interests are energy conversion machine and power conversion device design, control and application.

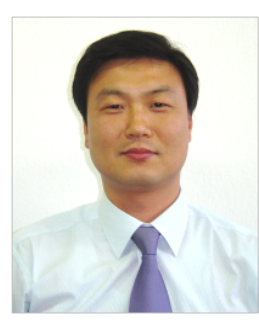

Tae-Uk Jung was born in Masan, Korea, in 1970. He received the B.S., M.S. and Ph.D. degrees in electrical engineering from Busan National University, Busan, Korea, in 1993, 1995 and 1999, respectively. Between 1996 and 2005, he was a Chief Research Engineer with Laboratory of LG Electronics, Korea. Between 2006 and 2007, he was a Senior Research Engineer of Korea institute of Industrial Technology, Korea. Since 2007, he has been with Kyungnam University as a Professor. Prof. Jung is a member of the Institute of Electrical Engineers of Korea (KIEE) and IEEE. 